\title{
Cultured Smooth Muscle Targets Lack Survival Activity for Ciliary Ganglion Neurons
}

\author{
Douglas J. Creedon and Jeremy B. Tuttle \\ The University of Virginia, Department of Physiology, Charlottesville, Virginia 22908
}

\begin{abstract}
Cultured neurons require specific trophic agents in order to survive. This dependence is thought to resemble the neuron-target interdependence that develops in vivo during synaptogenesis and neuronal cell death. The notion that neurons in general derive trophic support from their synaptic targets is based primarily on studies of peripheral neurons and motor neurons. To assess the general applicability of this nerve-target relationship, we tested the ability of vascular smooth muscle (VSM) to support dissociated neurons from the chick ciliary ganglion. The ciliary ganglion contains 2 distinct neuronal populations, one of which innervates striated muscle, the other VSM. Striated muscle cocultures are known to support all of the neurons in the ganglion for extended periods. Dissociated neurons were therefore cocultured in microwells containing VSM derived from the rat or chick aorta and from the choroid coat of the chick eye. Surviving neurons were counted after 1, 2, 5, and $7 \mathrm{~d}$. Striated muscle is able to support full neuronal survival in the same assay. However, in no case was VSM capable of contributing to neuronal survival in vitro. The neurons in the VSM cocultures were able to form neurites and make contacts with their putative targets, as confirmed by scanning electron and light microscopy. The presence of viable and differentiated smooth muscle cells was demonstrated in the cultures by transmission electron microscopy and analysis of smooth muscle $\alpha$-actin. The failure of VSM and even the chorold target tissue to support the survival of their innervating neurons suggests that novel mechanisms may operate to provide trophic support for neurons innervating VSM targets.
\end{abstract}

Neurons, especially peripheral neurons, embark upon a longterm symbiotic relationship with their targets at specific points in embryological development. This interdependence often begins during the period of normal neuronal cell death (Oppenheim, 1981; Purves and Lichtman, 1985). In the avian ciliary ganglion, neuronal death takes place between embryonic days 9 and 13, corresponding to Hamburger and Hamilton's (1951)

\footnotetext{
Received Aug. 27, 1987; revised Dec. 10, 1987; accepted Jan. 5, 1988.

We would like to acknowledge the services and expertise of Randal S. Blank and Thomas Eddinger in characterizing the smooth muscle cultures, and we wish to further thank Dr. Blank for his thoughtful review of the manuscript, and Susan Ramos of the Electron Microscopy facility for her time and technical assistance. This work was supported by BNS 8503276 from NSF and a grant from the American Heart Association, Virginia Affiliate. J.B.T. is the recipient of a Research Career Development Award (NIH NINCDS). D.J.C. is supported by NIH Training Grant 5 T32 HL-07284-10.

Correspondence should be addressed to Dr. Tuttle, Department of Physiology University of Virginia, School of Medicine, Box 449 Jordan Mcdical Education Building, Charlottesville, VA 22908.

Copyright (C) 1988 Society for Neuroscience $0270-6474 / 88 / 083100-11 \$ 02.00 / 0$
}

stages 35-39 (Landmesser and Pilar, 1974b). Approximately half of the ganglionic neurons degenerate, leaving some 3200 viable cells to function in the mature animal (Landmesser and Pilar, 1974b). The concept of a symbiotic relationship between a nerve and its synaptic partner derives, in part, from experimental manipulations affecting this developmental episode. Excising the optic vesicle between stages 16 and 20 , thus removing the peripheral innervation targets of the neurons, exacerbates neuronal death such that few neurons survive (Landmesser and Pilar, 1974a). However, neuronal cytological development is normal prior to the onset of cell death in the target-deprived ganglia (Pilar and Landmesser, 1976). Enlargement of the target via an implant increases the number of surviving neurons (Narayanan and Narayanan, 1978). Neuronal survival is also enhanced following reduction of interneuronal competition. This can be done by partial ablation of the neuronal population via selective axotomy-induced cell death (Pilar et al., 1980). The direct proportionality between neuronal survival and the amount of target available to each neuron suggests dependence upon the target, perhaps for the supply of trophic survival-supporting material (Oppenheim, 1981; Purves and Lichtman, 1985). The temporal coincidence of synaptogenesis with developmental cell death of motor neurons suggests a role for synapse formation or some other related interaction in the initiation and regulation of this nerve-target dependence. Selective access to trophic material, rather than synapse formation, may regulate survival of sensory neurons (Hamburger et al., 1981).

Activity through newly formed or forming synaptic pathways also affects neuronal cell death. Blockade of neuromuscular transmission with any one of several drugs prevents or delays the normal loss of neurons in the ventral motor column (Pittman and Oppenheim, 1978, 1979; Olek, 1980) and the trochlear nucleus (Creazzo and Sohal, 1979). Chronic stimulation accelerates the process and causes excessive cell death (Oppenheim and Nuñez, 1982). Activity may also regulate neuronal survival in the ciliary ganglion (Meriney et al., 1985, 1987). Preganglionic neurons of the ciliary ganglion (Wright, 1981; Meriney et al., 1987) and afferent nerves that synapse on spinal motor neurons (Okado and Oppenheim, 1984) also affect the cell death process, although their role is presumed to be more subtle and complex. These results implicate synaptogenesis and the signal traffic through the embryonic synapses as elements in motor neuron nerve-target symbiosis. For both motor and sensory neurons, survival is regulated by interaction with extrinsic factors associated with the target tissue.

Cell culture has proven to be a valuable tool in the investigation of nerve-target interdependence. Neurites have been shown to induce the formation of membrane patches of muscle 
acetylcholine receptors (Fischbach et al., 1984). Newly inserted receptors are apparently directed to the sites of nerve-muscle contact (Role et al., 1985). Contact with the muscle influences neuronal receptor metabolism (Crean et al., 1982; Tuttle, 1983) and neuronal transmitter synthesis (Tuttle et al., 1983; Gray and Tuttle, 1987). These in vitro studies support the notion that neuron-target interactions are developmentally important. Furthermore, they establish cell culture as a means for investigating such issues. Both in vivo and in vitro studies suggest that the interaction between peripheral neurons and their target cclls regulates survival and subsequent development via trophic exchange.

The avian ciliary ganglion consists of 2 neuronal populations that innervate distinct targets (Marwitt et al., 1971). The ciliary neurons contact the ciliary body and the iris, both striated muscle in the chick. The choroid neurons innervate the smooth muscle of the vessels in the choroid coat. Meriney and Pilar (1987) describe the morphology of the choroid and the pharmacology of the innervation of its vessels. The choroid is a vascular plexus with large lacunae. In the bird, with an avascular retina, the innermost choroid vessels comprising the choriocapillaris supply nourishment and oxygen to the retinal layers. The choroid is also thought to be involved in regulating the transretinal potential and intraocular pressure. Since the choroid nerves participate in the regulation of the ocular microcirculation, this inncrvation may contribute to the various functional roles of the choroid. Relatively little is known concerning the trophic traffic and interdependence of neuron-smooth muscle pairs, and almost nothing is known of how these affect the status of the vessels and the function of both the muscle and the innervating neurons.

Dependence of choroidal neurons on their target was first demonstrated by the target ablation experiments of Landmesser and Pilar (1974a). However, Meriney and Pilar (1987) report that, in contrast to the case with ciliary neurons, transmission at the peripheral junctions of choroidal cells does not begin until after cell death has begun. Furthermore, neuromuscular blockade does not influence cell death in the choroid neurons of the ganglion, while blockade reduces the death of ciliary neurons (Meriney et al., 1987). Different regulatory mechanisms appear to be involved during cell death in 2 neuronal populations of the same ganglion. This study examines the matter further by assessing the ability of cultured vascular smooth muscle (VSM) cells and cultured choroidal tissue to promote survival of dissociated ciliary ganglion neurons. The experiments are a direct test of target dependency in the neuron-smooth muscle relationship. The results indicate that the source of trophic support from the choroidal target is obscure, and that the role of the larget muscle in the process of regulated cell death is unclear.

Some of this work has appeared previously in abstract form (Creedon and Tuttle, 1986).

\section{Materials and Methods}

Cell cultures. Ciliary ganglia were isolated and cultured as previously described (Tuttle et al., 1980; Gray and Tuttle, 1987). The ganglia were removed by microdissection from chick embryos incubated for 9-10 d, Hamburger and Hamilton (1951) stage 35-36, and placed in sterile, modified Tyrode's saline (in mM: $130 \mathrm{NaCl}, 3 \mathrm{KCl}, 20 \mathrm{NaHCO}_{3}, 4$ $\mathrm{CaCl}_{2}, 1 \mathrm{MgCl}_{2}, 12$ glucose, $10 \mathrm{HEPES}$, and $0.5 \%$ antibiotic-antimycotic mix; Gibco Laboratories, Grand Island, NY). After all of the ganglia had been dissected, they were transferred to a $0.08 \%$ solution of trypsin (Sigma Chemical Co., St. Louis, MO) in $\mathrm{Ca}^{2+}$ - and $\mathrm{Mg}^{2+}$-free (CMF) Tyrode's and incubated for $10 \mathrm{~min}$ at $36^{\circ} \mathrm{C}$. The trypsin solution was then replaced with standard medium, consisting of Eagle's MEM (Gibco) supplemented with 10\% (vol/vol) heat-inactivated horse serum (Gibco), $1 \%$ MEM amino acid mix (Gibco), concentrated 50 times, $1 \%$ MEM vitamin mix (Gibco), and $0.5 \%$ concentrated 100 times, antibioticantimycotic mix (Gibco), concentrated 100 times. The ganglia were triturated with a fire-polished Pasteur pipette to obtain a single-cell suspension and plated into 24-well plates (Linbro, McLean, VA). Each microwell had been coated with collagen by adding and then aspirating a rat tail tendon solution (acid-soluble extract, dialyzed $24 \mathrm{hr}$ ). The collagen was dried under ammonia vapor and sterilized overnight with UV radiation. For coculture experiments, pectoral muscle, smooth muscle, or tissue from the choroid was plated (see below) onto the collagen before the ncurons were added. Each $16 \mathrm{~mm}$ microwell received the dissociate of 2 ganglia in a final volume of $0.75 \mathrm{ml}$ of standard medium.

The coculture experiments required tissue from several different sources. VSM cells were derived from thoracic aorta of either the rat (RVSM) or the chicken (CVSM). The cultures were established according to the procedures of Owens et al. (1986). The RVSM cultures were initiated and maintained by the Cell Culture Core facility of the program project, "Fundamental Studies of Vascular Smooth Muscle." Male Sprague-Dawley rats (Hilltop Lab Animals, Scottdale, PA) were asphyxiated with $\mathrm{CO}_{2}$ and their thoracic aortas were excised and placed in Hanks' balanced salt solution (HBSS; Gibco). The isolated vessels were cleared of excess fat and connective tissue via blunt dissection, cut longitudinally, and incubated in HBSS with $1 \mathrm{mg} / \mathrm{ml}$ collagenase (type II, $158 \mathrm{U} / \mathrm{mg}$; Cooper Biomedical, Freehold, NJ), $0.25 \mathrm{mg} / \mathrm{ml}$ elastase (type I, $3 \mathrm{U} / \mathrm{mg}$; Cooper), $1 \mathrm{mg} / \mathrm{ml}$ soybean trypsin inhibitors (Cooper), penicillin $(100 \mathrm{U} / \mathrm{ml})$, and streptomycin $(100 \mu \mathrm{g} / \mathrm{ml})$ for $15-$ $20 \mathrm{~min}$ at $36^{\circ} \mathrm{C}$. Under a dissecting microscope, the adventitia was removed and the luminal surface of the aorta was scraped with forceps to remove endothelial cells. The resulting strips were then minced and incubated in a fresh enzyme solution for $1.5-2.0 \mathrm{hr}$, with trituration at $30 \mathrm{~min}$ intervals. At the end of the incubation period, the resulting solution was filtered through an $85 \mu \mathrm{m}$ stainless steel mesh into $20 \%$ fetal calf serum (FCS; Gibco) to halt the enzyme activity. The cells were centrifuged (118 gm, $8 \mathrm{~min}$ ) and resuspended in medium 199 (Gibco) with $10 \%$ FCS and antibiotics. To establish the CVSM cultures, the same procedure was followed, except that Tyrode's was used instead of HBSS and the cells were resuspended in standard medium supplemented with $5 \%(\mathrm{vol} / \mathrm{vol})$ chick embryo extract [CEE; prepared according to Paul (1970), except that Tyrode's was used instead of HBSS]. Aortas for the CVSM were taken from 14-17-d-old chickens after they had been killed by decapitation. Once resuspended in medium, cells for the RVSM and CVSM cultures were counted with a hemocytometer and seeded at a density of $1.0-5.0 \times 10^{4}$ cells $/ \mathrm{cm}$.

RVSM cells were maintained in medium-199, supplemented with $10 \%$ FBS (Gibco) and antibiotics, in plastic tissue culture dishes (Corning Glass Works, Corning, NY), and harvested for passage when confluent. On the third or fourth passage, 1 week prior to the addition of neurons, the RVSM was plated into microwells containing standard medium with $2 \%$ CEE. Only primary cultures of the CVSM were used, and they were established as described above. As the VSM cells from either source reached confluency, they were maintained in standard medium lacking CEE. The CEE was removed a minimum of $24 \mathrm{hr}$ before the neurons were added to the microwells.

Neurons were also cocultured with tissue from the choroid coat of the eye. The tissue was taken from $16 \mathrm{~d}$ chick embryos because the pigmented epithelium could be readily removed at this age. The embryos were decapitated and the eyes carefully removed and placed in a dissecting dish with cold Tyrode's solution. The iris and ciliary body were excised and, with the lens and vitreous body, discarded. At the choroid fissure, the 3 layers of the eye meld, so this was snipped away to facilitate removal of the retina. The pigmented epithelium that remained after lifting the retina was gently scraped off with a pair of forceps. Any segments of the choroid with residual pigmented epithelium were cut away to avoid contaminating the cultures. The choroid could then easily be separated from the underlying sclera. After all the desired tissue was collected, the Tyrode's was replaced with solution containing $3 \mathrm{mg} / \mathrm{ml}$ collagenase (type IV, Sigma) and the tissue was incubated at $36^{\circ} \mathrm{C}$ for 1-2 hr. This was followed by a $10 \mathrm{~min}$ incubation with $0.08 \%$ trypsin in CMF Tyrode's. The trypsin was diluted with excess Tyrode's and, as described above, the sample was centrifuged, resuspended in standard medium with $5 \% \mathrm{CEE}$, triturated, counted, and plated at a density of $1-2 \times 10^{4} \mathrm{cells} / \mathrm{cm}$.

Survival assay. Neuronal survival was followed for $7 \mathrm{~d}$ after the neurons were dissociated and plated. The ability to support neurons was tested for the VSM populations and the choroid tissue by coculturing 
neurons with each of these potential target tissues. Pectoral muscle, which has been shown to support essentially all of the neurons in the ganglion (Nishi and Berg, 1977), was used as a positive control. The pectoral muscle was prepared as previously described (Tuttle et al., 1983). Neurons cultured alone served as the negative control. Six random fields in each microwell were counted using a $20 \times$ objective. These counts were then used to estimate the total number of cells per well. Counts were conducted after $1,2,5$, and $7 \mathrm{~d}$ and the microwell totals were averaged to yield a value for each of the culture conditions. The results are presented as the mean value \pm SEM. The results were compared using Student's $t$ test for differences between means.

Contractile protein. Choroid tissue was assayed for actin to verify the existence of differentiated smooth muscle in these cultures. The resolution of the actin isoforms $(\alpha, \beta$, and $\gamma)$ was obtained with a modification of the technique of O'Farrell (1975) for 2-dimensional isoelectric focusing/sodium dodecyl sulfate (IEF/SDS) electrophoresis, as described by Fatigati and Murphy (1984) and Owens et al. (1986). After 1 week in culture, a sample of the choroid cells was frozen in an acetonedry ice slurry. Samples were later thawed and resuspended in the IEF buffer at $10^{3}-10^{4}$ cells $/ \mu$ l. After completion of the second dimension, the gels were stained with Coomassie brilliant blue (Fairbanks et al., 1971). Fractional isoactin content was determined by scanning the gel with a pinpoint light source of $525 \mathrm{~nm}$ with a Quik Scan Jr. customized with high-resolution optics (Helana Laboratories, Beaumont, TX), as described by Fatigati and Murphy (1984). Several passes over the gel assured that an optimal reading was obtained for each of the isoforms. The readings were then averaged to determine the relative amount of each isoform in the sample.

Electron microscopy. Culture samples were prepared for both transmission and scanning electron microscopy. The transmission electron microscopy was performed with the aid of the Department of Physiology EM facility. Samples were prepared according to the procedures of Purdy-Ramos and Forbes (1984). Cells were rinsed with HBSS (Gibco) and fixed using increasing concentrations of glutaraldehyde in HBSS: $0.5 \%$ for $10 \mathrm{~min}$ at $36^{\circ} \mathrm{C}, 1.0 \%$ for $10 \mathrm{~min}$ at $36^{\circ} \mathrm{C}, 1.5 \%$ for $10 \mathrm{~min}$ at $36^{\circ} \mathrm{C}$, and $1.5 \%$ for $20 \mathrm{~min}$ at $4^{\circ} \mathrm{C}$. The dishes were then rinsed twice with HBSS and postfixed with $1 \%$ osmium tetroxide for $60 \mathrm{~min}$ at $4^{\circ} \mathrm{C}$. For poststaining, 3\% uranyl acetate in $0.09 \mathrm{M}$ veronal acetate buffer was applied for $2 \mathrm{hr}$ at $4^{\circ} \mathrm{C}$. The samples were dehydrated in graded ethanol and embedded with a Poly/Bed 812 mixture (Polysciences, Warrington, PA). Thin sections were viewed with a Zeiss (Thornwood, NY) electron microscope. Sections for scanning electron microscopy were fixed as described above, but then dehydrated, critical-point dried, and sputtercoated in the Medical School Central EM facility. Sections were then viewed on a Jeol (Peabody, MA) scanning electron microscope.

Immunohistochemistry. Neurons were labeled by indirect immunofluorescence in order to assess the extent of neurite formation in the mixed cocultures, where direct observation is difficult. Cultures were established on polystyrene coverslips (collagen-coated) and maintained in medium supplemented with $5 \%(\mathrm{vol} / \mathrm{vol}) \mathrm{CEE}$. After the appropriate time in vitro, cultures were fixed at $36^{\circ} \mathrm{C}(20 \mathrm{~min})$ in $3 \%$ aldehyde fixative in PBS ( $\mathrm{pH}$ 7.4). This was prepared in substantial lots from paraformaldehyde from a lot selected for low-autofluorescent induction and aliquots stored frozen until use. Following fixation and $2(5 \mathrm{~min})$ washes in PBS, the cultures were delipidated by $5 \mathrm{~min}$ in $0.4 \%$ Triton $\mathrm{X}-100$ in PBS, and the detergent then removed by repeated washes in PBS. Nonspecific serum protein interactions were reduced by an incubation step in 5\% BSA (Sigma) in PBS. The primary probe was a monoclonal antibody directed against a neuron-specific form of beta-tubulin (Frankfurter et al., 1986; Lee et al., 1987) that has been found to specifically and reliably label postmitotic ciliary ganglion neurons. A $30 \mathrm{~min}$ incubation in the antitubulin (1:500 in 0.5\% BSA in PBS) and washes was followed by a $60 \mathrm{~min}$ incubation in a rhodamine-conjugated anti-mouse IgG raised in goat (Hyclone) (1:20 in $0.5 \%$ BSA). After a final series of washes, the coverslips bearing the labeled cultures were inverted and mounted on slides in $90 \%$ glyccrol for vicwing and photography under epifluorescence microscopy.

\section{Results}

The results of the control conditions for the neuronal survival assay appear in Figure 1. Within $24 \mathrm{hr}$, an obvious difference was evident between the neurons remaining in coculture with striated muscle and those cultured alone in the trophically deficient medium, although the wells had been plated with equal

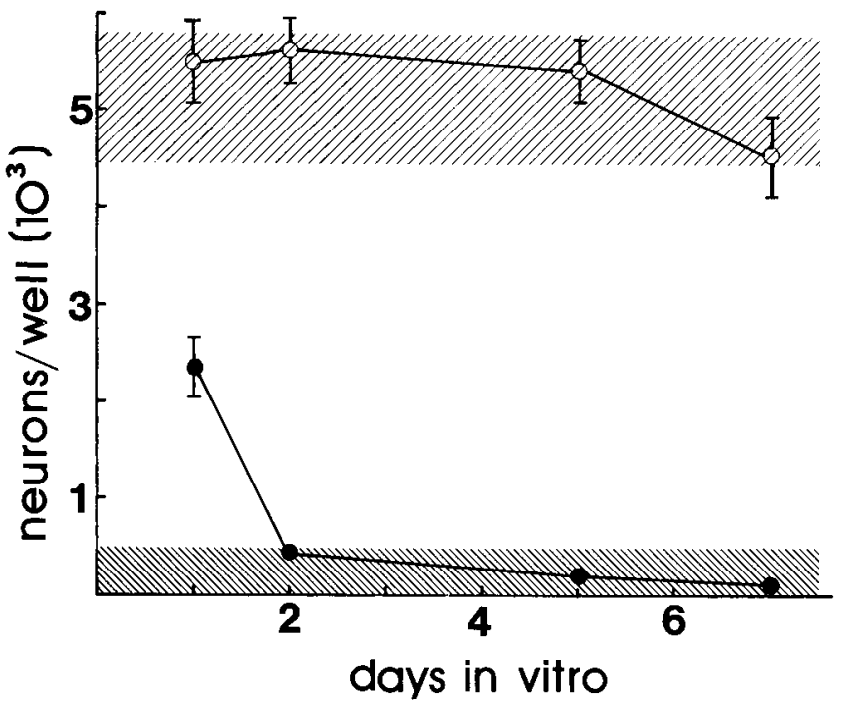

Figure 1. Control conditions of the neuronal survival assay. Dissociated ciliary ganglion neurons were plated into microwells containing a trophically deficient medium. Either collagen or live myotubes served as the substrate. The number of viable cells was counted in 6 random microscopic fields per well and used to estimate the total number of cells in the well. Counts were performed on days $1,2,5$, and 7 , and recorded as the mean total \pm SEM. All of the neurons plated survived the full $7 \mathrm{~d}$ in the myotube cocultures (open circles, $n=30$ ). The basal medium alone (closed circles, $n=33$ ) provided essentially no trophic support and no neuronal survival.

numbers of neurons. The neurons in the trophically deficient medium (Fig. 1, filled circles) continued to rapidly disappear, and few remained after the second day. On the other hand, the pectoral muscle cultures (Fig. 1, open circles) supported the neurons for the duration of the study; there was no statistical difference between the counts on day 1 and day $7(p>0.1)$. Photomicrographs of these cultures demonstrate that, in addition to the numerical differences, morphological differences were also apparent (Fig. 2). After $1 \mathrm{~d}$, the neurons in the trophically deficient medium (Fig. $2 a$ ) remained rounded and, for the most part, devoid of neurites. Conversely, many of the neurons cocultured with straited muscle sent out extensive processes during the first $24 \mathrm{hr}$ (Fig. $2 b$ ). Furthermore, the neurons tended to lose their spherical shape as they firmly attached to their substrate. After a week in coculture (Fig. $2 c$ ), the neurons maintained a normal appearance, similar to that on the first day. Although not evident in Figure $2 c$, the neurons continued to ramify the neuritic network. The pectoral muscle provided for the survival of $100 \%$ of the neurons plated, while the standard medium was entirely deficient. These culture conditions were thus used to assess the ability of other potential sources of trophic support.

If the existence of a symbiotic relationship between nerves and their targets is universal, then VSM would also be expected to provide trophic support for ciliary ganglion neurons. The ganglion innervates VSM and removal of the eye exacerbates cell death (Landmesser and Pilar, 1974a). However, in the experiments reported here, this was not the case. When neurons wcre cocultured with VSM derived from the aorta of either the rat or the chicken, the neurons died within $5 \mathrm{~d}$ (Fig. 3). The decreased level of support is barely evident $24 \mathrm{hr}$ after the neurons were plated. After $2 \mathrm{~d}$, the number of neurons had dwindled significantly. After $5 \mathrm{~d}$, the number of neurons surviving in the cocultures with RVSM and CVSM could not be distinguished from the negative controls. Phase-contrast photomicrographs 

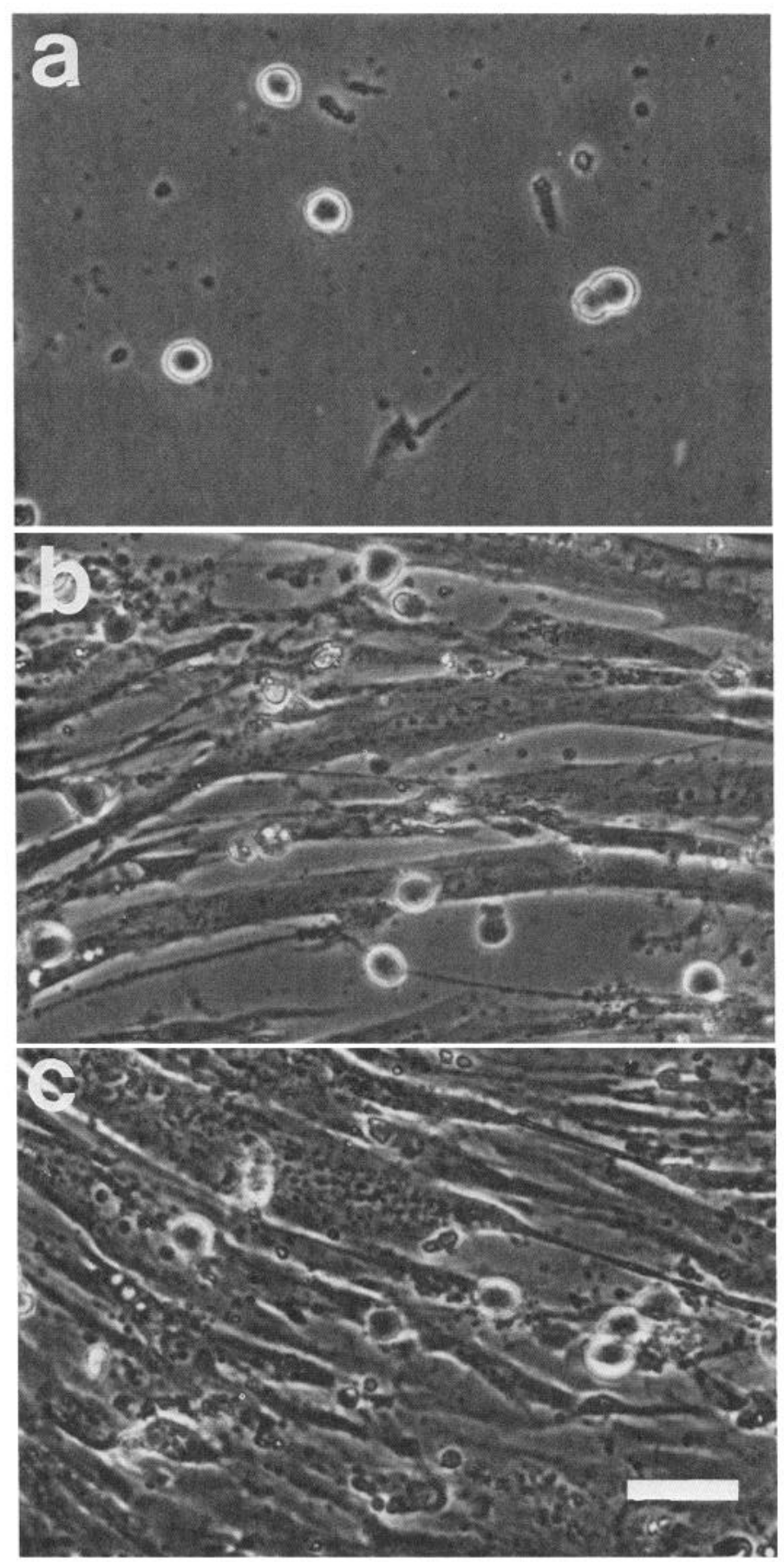

Figure 2. Phase-contrast photomicrographs of dissociated ciliary ganglion neurons cultured alone or cocultured with striated muscle. $a$, Neurons cultured alone after $24 \mathrm{hr}$ appear rounded and rarely extend neurites. $b$, Neurons cocultured with striated muscle myotubes after $24 \mathrm{hr}$ take on a more oval shape as they attach to the underlying myotubes. An extensive neuritic network has begun to form. $c$, Cocultured neurons after $7 \mathrm{~d}$ in culture appear no different from those at day 1 . The extent of the neuronal processes is not visible in this photomicrograph. Bar, $50 \mu \mathrm{m}$.

reveal that after $2 \mathrm{~d}$ in culture, those neurons cocultured with either RVSM or CVSM remained sitting atop the smooth muscle layer, with few neurites apparent (Fig. 4, $a, b$ ). Neurons seemed capable of extending neurites, but their extent was typically obscured by the underlying muscle layer. Neurons in these cultures also showed signs of secure attachment, as many assumed

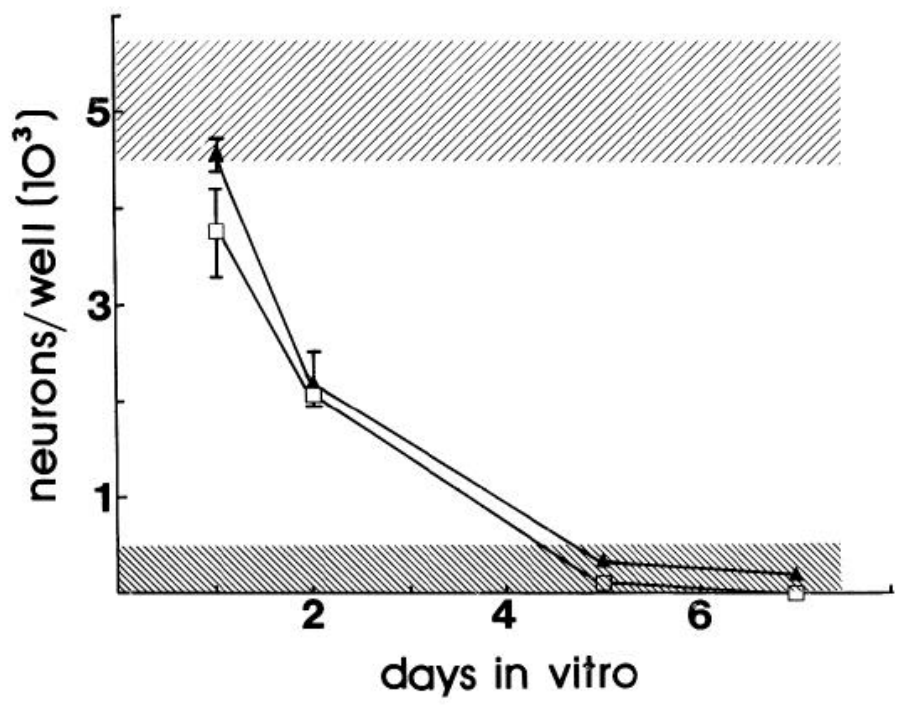

Figure 3. Neuronal survival assay for vascular smooth muscle (VSM) cocultures. Dissociated neurons were plated onto a confluent layer of VSM derived from the aortas of the rat (triangles, $n=22$ ) or the chicken (squares, $n=6$ ). The shaded regions mark the approximate levels of full survival and minimal survival, as indicated by the control assay (Fig. 1). Apparently more neurons survive the first $24 \mathrm{hr}$, but the number of neurons remaining on day 2 is markedly different from that in the striated cocultures $(p<0.001)$. The number of surviving neurons continued to decline as the experiment progressed.

a nonspherical morphology. Despite these early adaptations to the coculture, the neurons were unable to obtain trophic support.

When neurons were cultured with a monolayer of tissue from the choroid coat of the embryonic chick, the results were similar to those with the other sources of VSM. In this case, however, there was an obvious difference in survival from the skeletal muscle control as early as at $24 \mathrm{hr}$ (Fig. 5). In fact, the number of neurons was as low as the number cultured alone $(p>0.1)$. The counts on days 2 and 5 were slightly higher than those of the neurons alone $(p<0.5)$, but it was clear that if there was any support, it was minimal. At $24 \mathrm{hr}$, the neurons appeared healthy, but were more like those plated directly on collagen (Fig. 4c). Like the neurons cocultured with the VSM, only an occasional neurite was seen, and its course was difficult to follow in the phase-contrast images.

The few neurons that remained on day 2 in standard medium alone were typically rounded, with few, if any, processes (Fig. $2 a$ ). Phase-contrast images suggested that the same was probably true for neurons plated on the smooth muscle targets. Upon a closer look, however, scanning electron micrographs indicated that this was not the case for ciliary ganglion neurons cocultured with tissue from the choroid (Fig. 6). After $1 \mathrm{~d}$, it was clear that the neurons were capable of extending neurites and did not appear grossly different from counterparts on skeletal muscle (Fig. 6a). This finding was further strengthened by the photomicrographs of the neurons labeled with the neuron-specific tubulin antibody (Fig. 7). Again, there was little apparent difference between the neurons plated on choroid (Fig. 7a) and those plated on pectoral muscle (Fig. $7 b$ ). Both displayed a neuronal network, including potential terminal endings and contact sites with the target. In the choroid coculture, this network is short-lived. Although the choroid tissue does not provide trophic survival support, it does provide a suitable substrate for the elaboration of neuronal connections. The observation that 

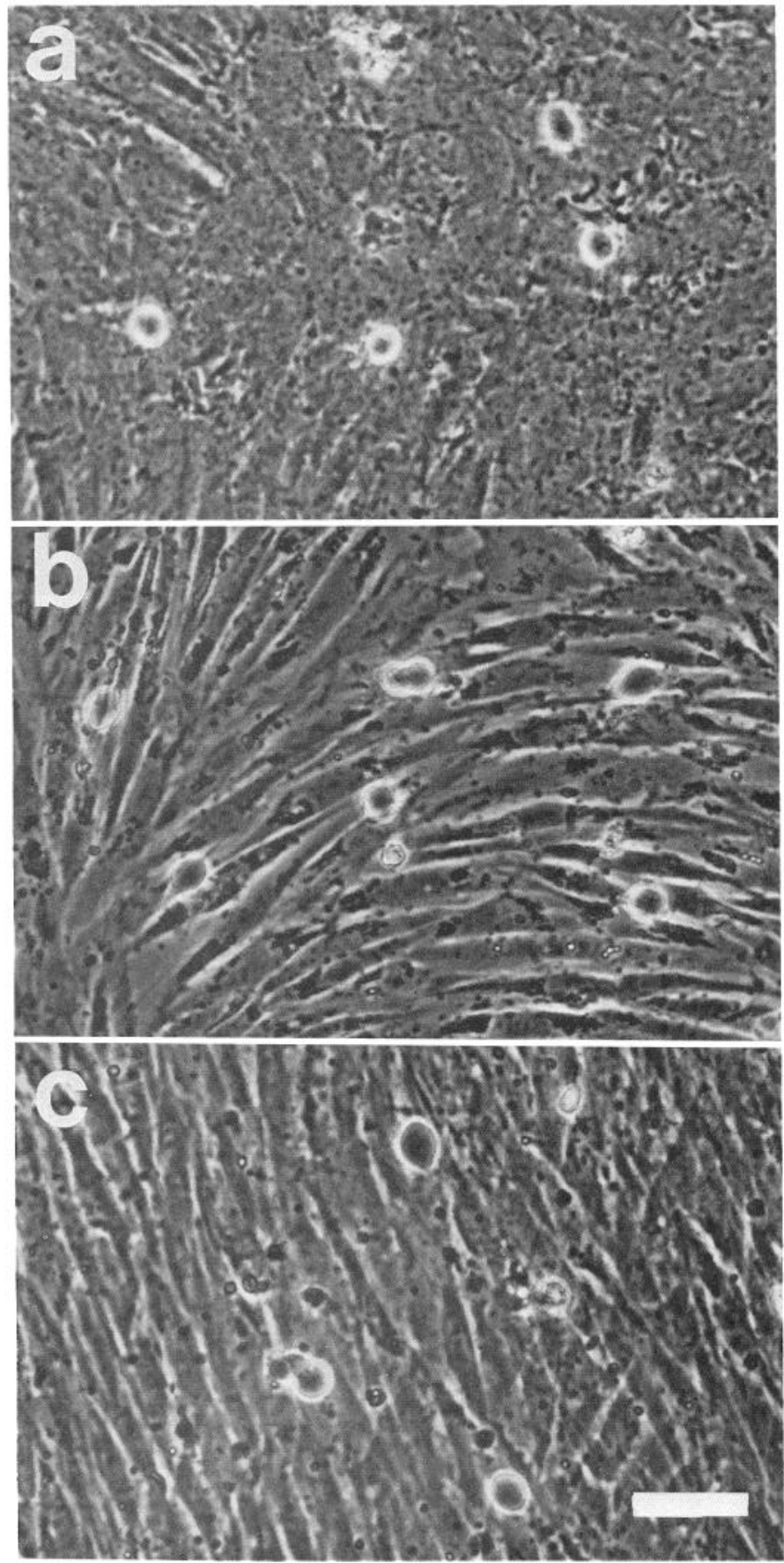

Figure 4. Phase-contrast photomicrographs of neuron-VSM cocultures after $24 \mathrm{hr} . a$, RVSM cocultures. $b$, CVSM cocultures. $c$, Choroid cocultures. The neurons do not appear substantially vastly different from those plated on collagen in the deficient medium (Fig. $2 a$ ). Some of the neurons do, however, appear to be extending neurites. Bar, $50 \mu \mathrm{m}$.

the neurons readily form neurites suggests that the coculture environment is not sufficiently hostile to prevent neurite initiation and outgrowth.

The cultured VSM used in these experiments may not be representative of the ganglionic target. The neuron-target hypothesis presumes that it is the target cell that is involved in the trophic interaction. The cocultures must therefore be shown to contain smooth muscle cells in order for the experiments to test the hypothesis. The RVSM and CVSM cultures were both

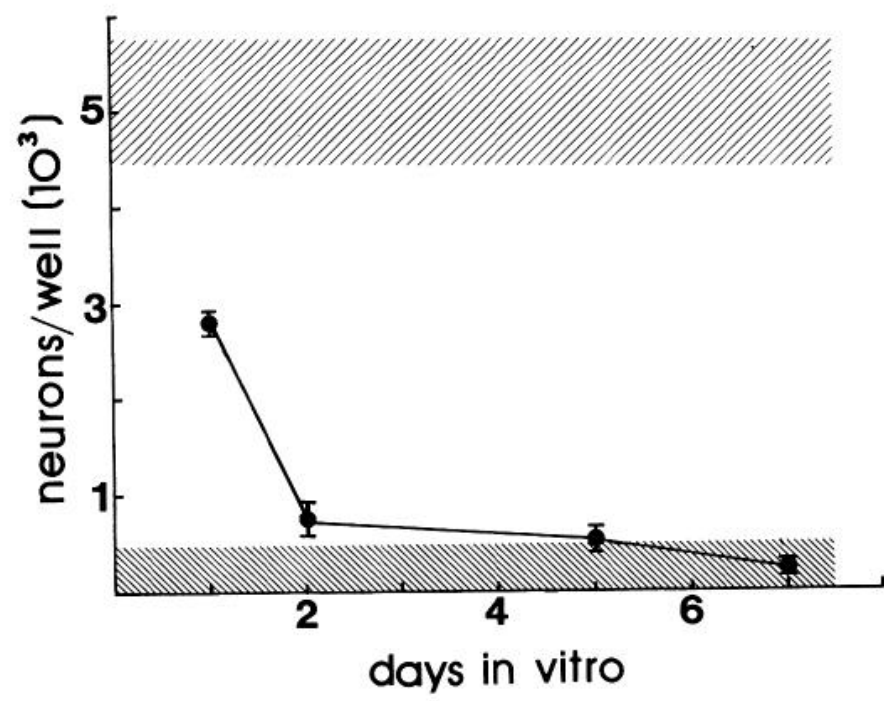

Figure 5. Neuronal survival in choroid tissue cocultures $(n=22)$. The survival profile on the choroid cultures parallels that of the negative control. Counts from the choroid cocultures did not differ from those on the collagen $(p>0.1)$. The choroid tissue seems incapable of providing even a minimal amount of trophic support, despite the fact that the culture is derived from a ganglionic target. Even the short-term support that may be available in the CVSM and RVSM cocultures is lacking in the choroid monolayer.

derived from the media of the aorta, which contains predominantly smooth muscle cells. In addition, the RVSM has been extensively characterized in previous studies (see ChamleyCampbell et al., 1979; Purves, 1981). The CVSM cells, while taken from the same, relatively pure source of smooth muscle, have not been studied as extensively. Transmission electron micrographs were therefore used to demonstrate the existence of VSM cells in these cultures. After only $4 \mathrm{~d}$, the cells contained substantial amounts of actin fibrils with dense bodies (Fig. 8c), characteristic of VSM in vivo and in vitro (Chamley-Campbell et al., 1979). Fibroblasts and other cell types will also demonstrate such actin bundles at sites of attachment with the culture vessel. In fibroblasts, however, the actin is not aligned parallel with the long axis of the cell, nor do these cells have thick filaments associated with the dense bodies (Fig. 8e). The cultures of CVSM cells thus contained functional potential target cells for the neurons.

The choroid cultures also contained cells matching the VSM profile (Fig. 8, $a, b$ ), suggesting that these cultures contained potential target cells. As further verification of the presence and state of differentiation of the smooth muscle cells, the choroid cultures were analyzed for the presence of $\alpha$-actin. This isoform of actin is smooth muscle-specific and expression of $\alpha$-actin is related to the growth state of the cells (Owens et al., 1986). Fifteen percent of the actin in the cultures was smooth musclespecific $\alpha$-actin (Fig. 9). This result suggests that a substantial proportion of the culture derived from the choroid was comprised of differentiated VSM cells. Therefore, the target cells of the choroidal neurons were present, yet unable to provide for neuronal survival.

\section{Discussion}

Negative results, especially those obtained in cell culture, demand particular care in interpretation. This may be especially true with respect to cell survival. Ciliary ganglion neurons can 

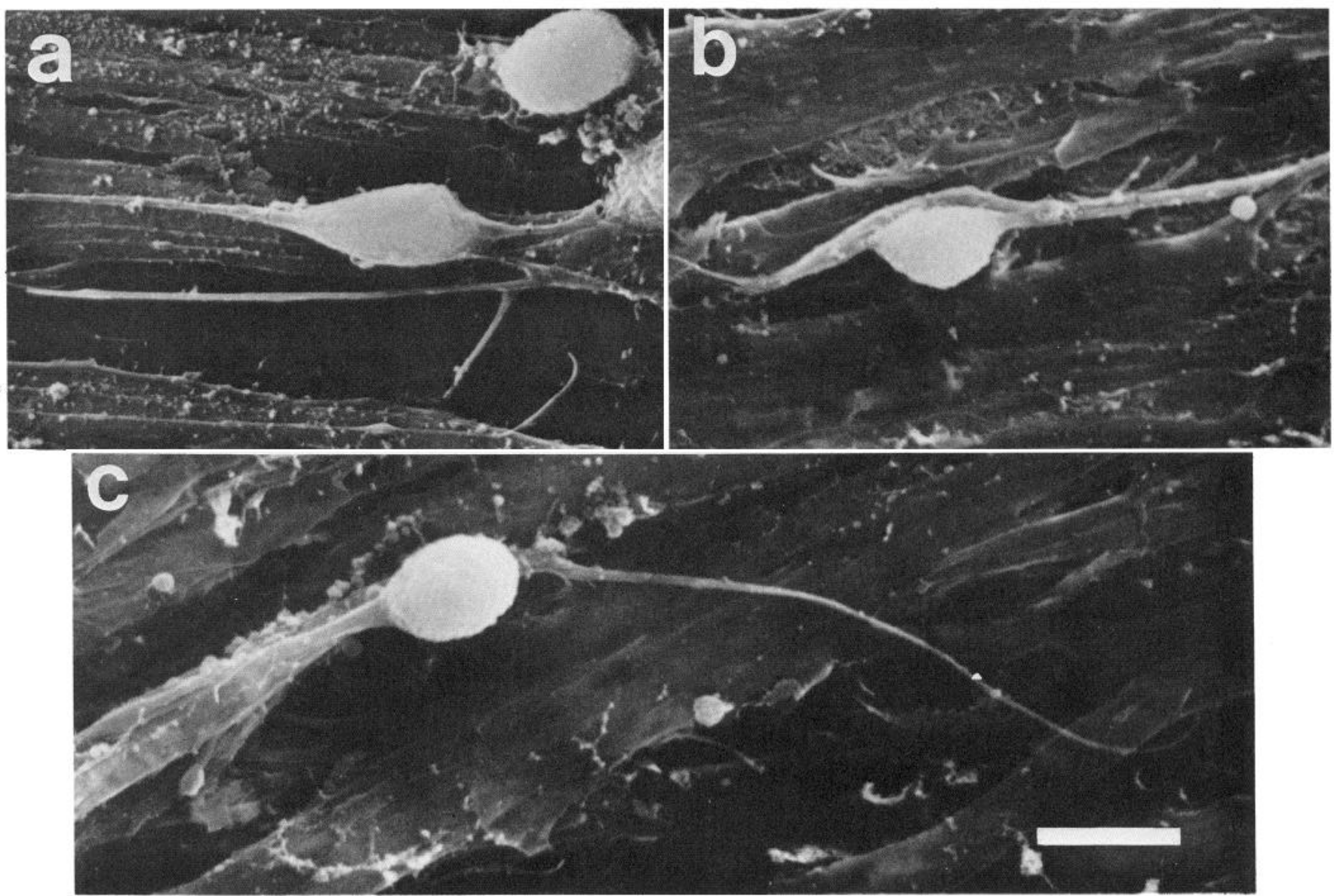

Figure 6. Scanning electron micrographs of neurons cocultured for $24 \mathrm{hr}$ with striated muscle $(a)$ and choroid tissue $(b, c)$. Although neurons derive no trophic support from the cultured choroid cells, those that survive are capable of extending neurites and interacting with the substrate. Bar, $10 \mu \mathrm{m}$.

die in culture for a variety of reasons, perhaps the least likely of which is a lack of trophic survival protein. On the other hand, neuronal survival necessarily implies the presence of some trophic substance. Helfand et al. (1976) first cultured dissociated ciliary ganglion neurons in MEM conditioned by heart cells and supplemented with fetal calf serum. Striated muscle-conditioned medium and coculture with striated muscle myotubes were also shown to support survival (Bennett and Nurcombe, 1979; Nishi and Berg, 1979). A component of chick embryo extract in conjunction with serum-supplemented medium can maintain cultured neurons for at least 3 weeks (Tuttle et al., 1980). No substitute has been found for the ciliary neuronotrophic factor (CNTF) found in CEE, but the serum requirement can be largely fulfilled by insulin (Skaper et al., 1984). The striated muscle and CEE apparently provide distinct trophic agents because the neuronal responses to serum and substrate differ for the 2 sources (Varon et al., 1979). Human serum alone will support ciliary ganglion neurons to a limited degree, but full support is only obtained in the presence of elevated potassium (Touzeau and Kato, 1983). The role for potassium was first tested to assess the role of activity on survival. Potassium depolarization delayed, but did not prevent, the demise of the cultured neurons (Bennett and White, 1979). Additional sources of trophic factors have been identified (Barde et al., 1983; Berg, 1984; Manthorpe and Varon, 1985), but a developmental role for any of these factors remains to be established. It is clear, however, that there are multiple sources of trophic, survival-supporting molecules for ciliary ganglion neurons. One would expect such molecules to be readily available from the tissue the neurons innervate.

Specific involvement of the target in neuronal survival was first proposed by Hamburger and Levi-Montalcini (1949). The discovery of nerve growth factor (NGF) and much subsequent work on this molecule indicate the validity of this notion (see Greene and Shooter, 1980; Thoenen and Barde, 1980; LeviMontalcini, 1982). For those neuronal populations not responsive to NGF, the results of target additions and ablations suggest a similar developmental interaction involving different trophic molecule(s) (Berg, 1982; Thoenen and Edgar, 1985). CNTF is thought to be this molecule for the ciliary ganglion and perhaps other neuronal populations (Manthorpe et al., 1985). CNTF is concentrated in a portion of the eye that contains the ganglionic target structures (Adler et al., 1979), and its production is increased and sustained as cell death in the ciliary ganglion is completed (Landa et al., 1980). The ability of CNTF to prevent all of the neurons dissociated from the ciliary ganglion from dying indicates that, in vitro, both neuronal populations in the ganglion are responsive to this trophic agent. Both targets should thus be able to produce this or some other trophic substance. Yet, the ciliary ganglion neurons obtained no support from the smooth muscle tissues cultured during the experiments reported here.

Coculture conditions could be adversely affecting the neurons, 

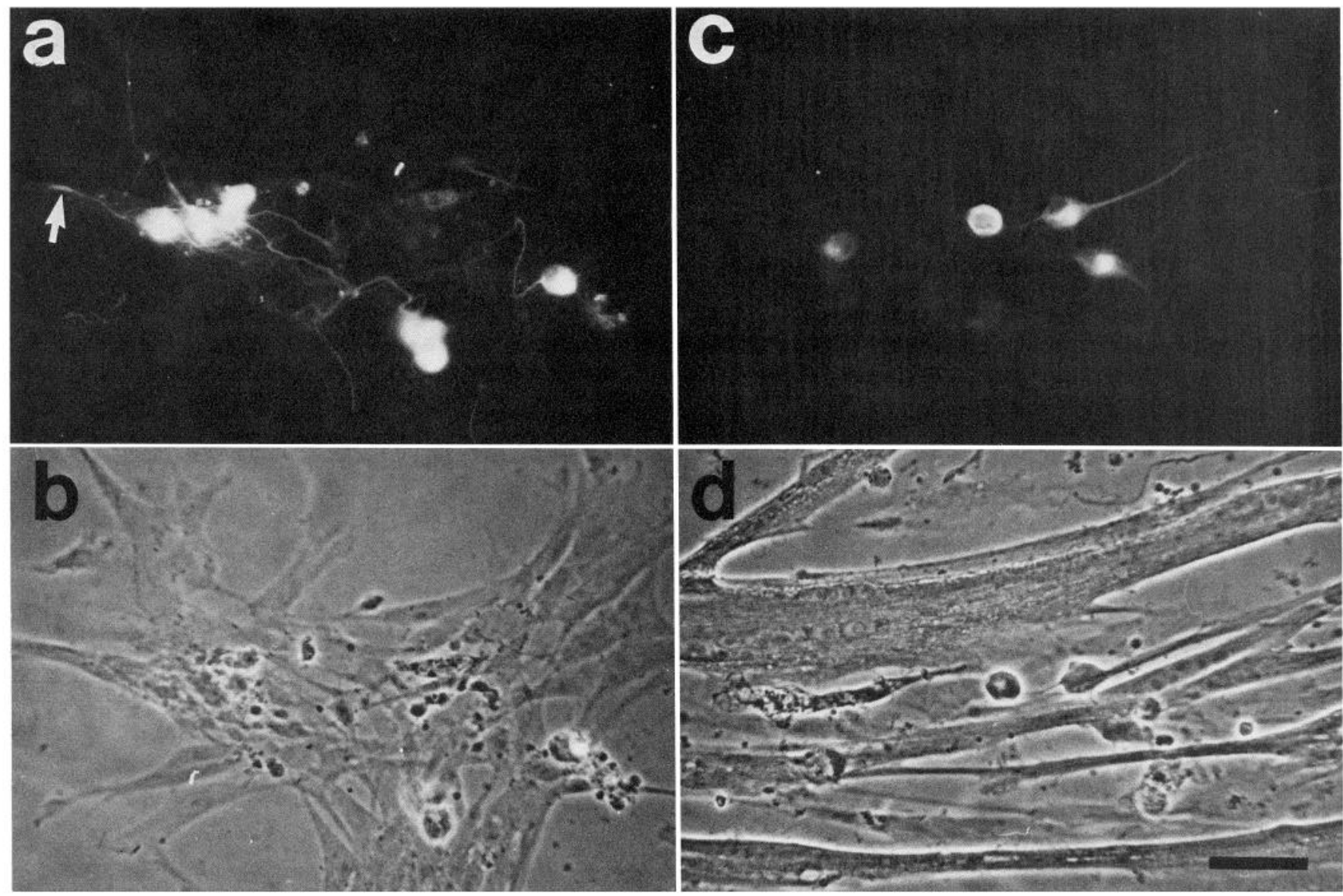

Figure 7. Light photomicrographs of neuronal cocultures stained with a neuron-specific tubulin antibody to reveal the extent of neuronal growth, and the corresponding phase-contrast image. The neurons cocultured with choroid tissue $(a, b)$ display an extensive neuritic network under fluorescence microscopy $(a)$ that is not evident in the phase-contrast photograph $(b)$. The neurites, however, do not have the varicosities or extensive branching characteristic of neurons maintained in supplemented medium. Instead, large swellings can be seen ( $a$, arrow) at terminal sites of contact with the underlying tissue. Neurons plated onto striated myotubes $(c, d)$ run their axons along the length of the myotubes and make similar swollen contacts. Bar, $50 \mu \mathrm{m}$.

thus negating any positive trophic effects of the smooth muscle. Alternatively, the tissues used for the cocultures might not be appropriate targets for the neurons. Barring these possibilities, a further explanation for the results could be that the target hypothesis for trophic support does not strictly apply to all neuronal populations.

Basic medium with serum has proven to be adequate for dissociated neurons only when supplemented with a trophic molecule. The basic medium is not thought to be antagonistic, but rather insufficient. In coculture, the smooth muscle cells might actively metabolize the available nutrients or produce a toxic substance. The ability to coculture ganglionic neurons with other active cell types argues against the first possibility. Nor is a toxic effect indicated, as the neurons can be successfully cocultured when CEE is present in the medium (results not shown). Either possibility is rendered more unlikely if we consider that those neurons that persist appear quite normal. The ability to extend neurites has clearly not been hampered (Figs. 4, 6, 7). Thus, smooth muscle does not seem to actively kill the neurons, but rather prevents survival by failing to provide the required trophic substance.

The failure of the VSM to produce demonstrable trophic support could, alternatively, result from transferring the choroid to a culture dish. The smooth muscle tissue that the choroid neu- rons encounter in vivo might produce a trophic substance that they fail to produce in vitro. Freshly cultured VSM cells enter a phenotypically modified state marked by a decrease in contractile protein synthesis (Chamley-Campbell et al., 1979). It is possible that the production of trophic molecules is down-regulated in a similar fashion. However, VSM cells "redifferentiate" when confluent, and they resume making contractile proteins (Gabbianni et al., 1984; Owens et al., 1986), as well as expressing high-affinity receptors (Gunther et al., 1982; Colucci et al., 1984) and responding electrically to agonists (Martin and Gordon, 1983; Colucci et al., 1984). The electron micrographs (Fig. 8) and the actin gels (Fig. 9) establish the presence of differentiated smooth muscle cells in the cultures. The choroid cultures may have also contained smooth muscle cells still modified or along the continuum leading to full differentiation, but the intact choroid and the cultures contained similar amounts of $\alpha$-actin relative to the total actin present. If the neurons require the presence of smooth muscle cells, the data indicate that these cells were available. Rather than the smooth muscle cells, some other aspect of the target tissue that is essential for neuronal survival might be missing.

Although the target cell is often presumed to be the source of the trophic factors, this has not always been demonstrated experimentally. Even NGF, by far the most well characterized of 

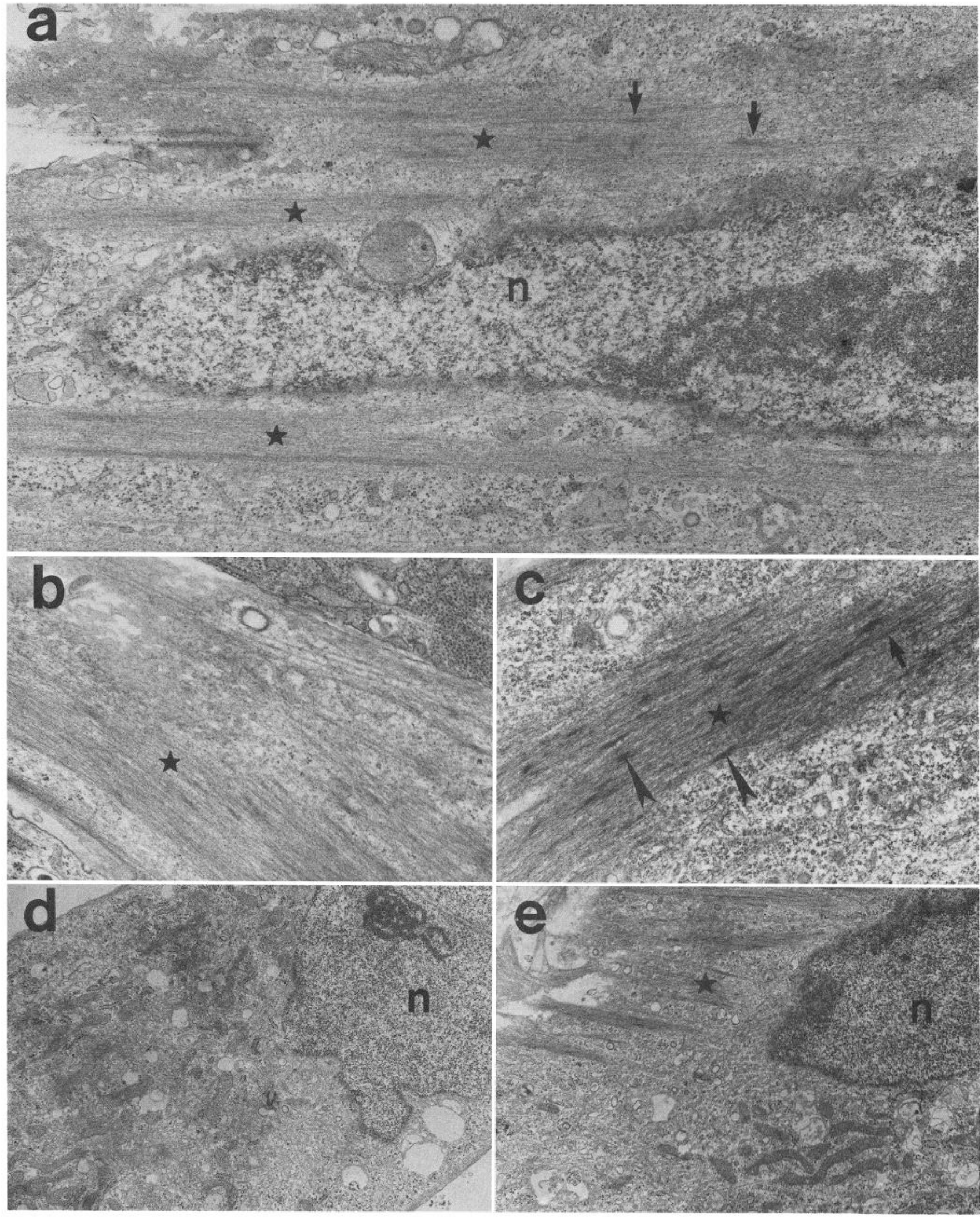

Figure 8. Transmission electron micrographs of cells used in the VSM cocultures. $a$, Typical smooth muscle cell from the choroid after 1 week in culture. Actin bundles (stars) running parallel to the nucleus $(n)$ and the long axis of the cell contain characteristic dense bodies (arrowheads). $b$, Another presumptive smooth muscle cell from a choroid culture, adjacent to a nonsmooth muscle cell. $c$, A representative sample of actin filaments from a smooth muscle cell in the chick VSM cultures. $d, e$, Fibroblastic cells from the choroid cultures. As opposed to the smooth muscle cells, their cytoplasm is filled with mitochondria, free ribosomes, and endoplasmic reticulum. Actin bundles can also be found in these cells (star, $e$ ), but only at the cut edges of cells. Magnifications: $\times 28,000(a) ; \times 16,000(b, c) ; \times 6000(d, e)$. 

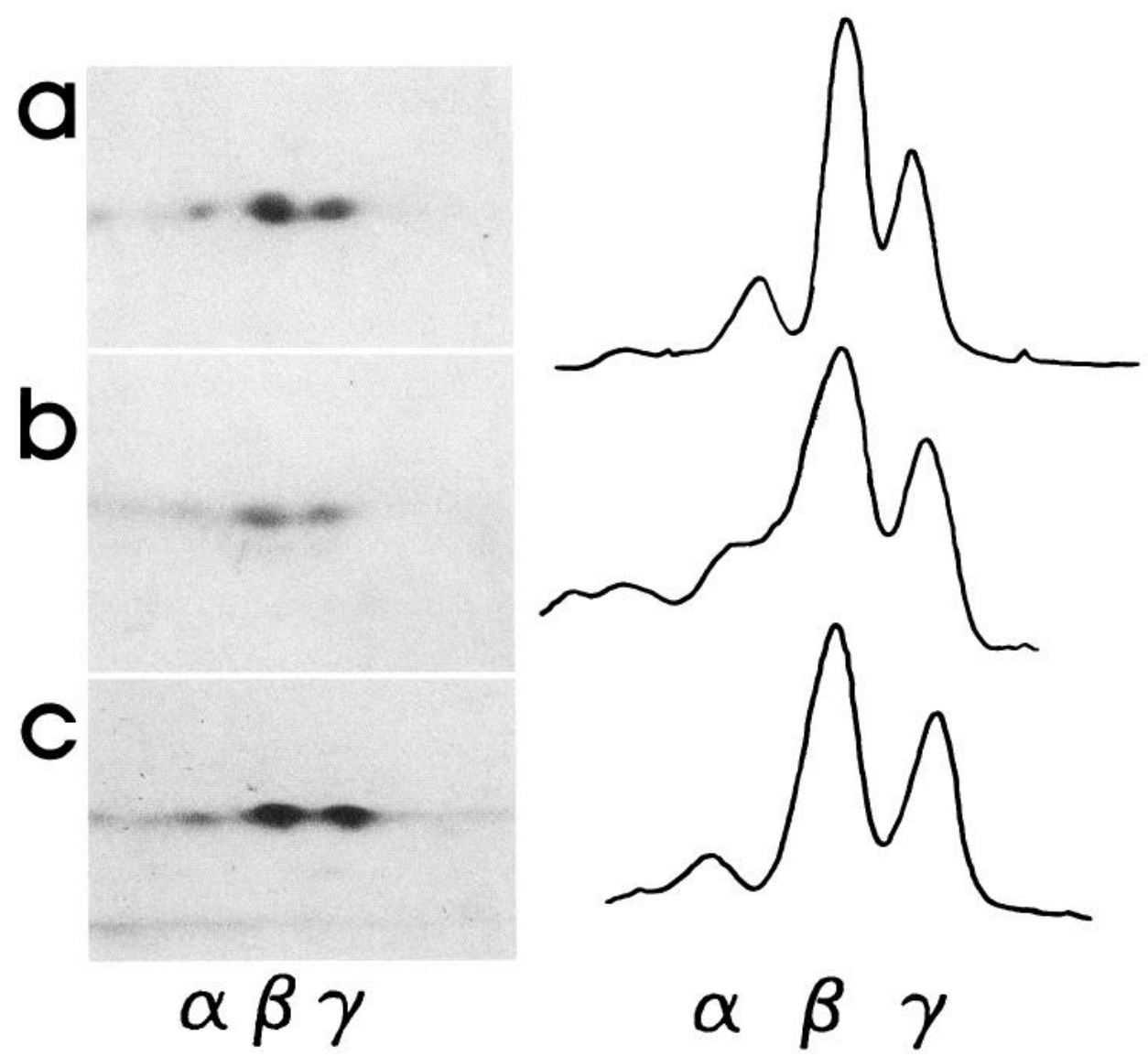

Figure 9. Two-dimensional gels of the fractional isoactin content of the choroid tissue at different stages in its preparation. $a$, Dissociated choroid after 1 week in culture, immediately prior to neuronal plating. $b$, Freshly dissociated choroid. $c$, Whole choroid. Traces of the scans appear on the right. The relative amount of $\alpha$-actin did not change from the whole choroid to 1 week in culture (15 vs $13 \%$, respectively). The freshly dissociated cells contained $8 \%$ $\alpha$-actin. The increase seen after 1 week in culture suggests that the culture conditions promote differentiation of the VSM cells. the trophic factors, has not been localized to the target cells of sympathetic or dorsal root ganglion nerves. There is a relationship between the amount of NGF in the target field and the density of innervation (Shelton and Reichardt, 1984; Davies et al., 1987), but there is, as yet, no indication that the target cell itself is responsible for the production and release of NGF. In fact, there is evidence to the contrary. The increase in NGF production in the iris upon denervation (Ebendal et al., 1980) has been attributed to the Schwann cells (Rush, 1984). Similarly, the fibroblasts are thought to be responsible for NGF production by cultured heart tissue (Furukawa et al., 1984). With these findings in mind, the relatively pure VSM populations derived from the aortas of rats or chickens might not be expected to provide support. The choroid cultures, however, contained at least some of the additional cell types found in the intact tissue. If one of these cells or an interaction of several cell types was required, the choroid cultures would be more apt to provide the appropriate interaction(s). The precise relationship between the cultures and the intact choroid was not established. The possibility that the cultures lacked some element therefore remains. Activity in the choroid does not seem to play the same role in cell death as does activity in the ciliary body and iris (Meriney et al., 1987). The inability to derive support from the cultured choroid is even more puzzling given that other, nontarget, tissues, such as bovine heart (Bonyhady et al., 1980) and rat hippocampus (Heacock et al., 1986), produce CNTFs. This does not preclude the possibility that the cultured choroid is modified sufficiently to prevent it from performing its trophic role. It does, however, question whether or not the target-trophic hypothesis is applicable to all neuronal populations.
For the ciliary neurons, the coincidence of synaptogenesis and neuronal cell death, and the role of activity in cell death imply the involvement of specific nerve-target interactions in this developmental episode (Landmesser and Pilar, 1978; Meriney et al., 1987). The same appears true for other motor neurons, including those of the lateral motor column of the spinal cord (Pittman and Oppenheim, 1978, 1979; Olek, 1980) and of the trochlear nucleus (Creazzo and Sohal, 1979). In addition to activity, the in vitro support obtained from striated muscle involves contact with the muscle membrane (D. J. Creedon and J. B. Tuttle, unpublished observations). The innervation of smooth muscle is markedly different from that of striated muscle, and this may account for the apparent differences highlighted in these studies. Neurites extend into the choroidal target field by the onset of cell death (stage 34), but transmission is not detectable until stage 36 and cannot be repeatedly recorded until stage 40 (Meriney and Pilar, 1987). Blockade of neuromuscular activity has no effect on choroidal neuron survival, while blockade of ciliary synapses, functional at stage 38 , profoundly alters neuronal survival. The lack of definitive junctional structures at VSM synapses may result in an altered neuron-target relationship.

Although the 2 neuronal populations apparently respond differently to manipulations of target interaction, they share a common response to interruptions in preganglionic transmission. Ganglionic blockade typically enhances cell death (Wright, 1981; Okado and Oppenheim, 1984), and this holds for both populations of neurons in the ciliary ganglion (Meriney et al., 1987). Ablation of the preganglionic inputs to the ciliary ganglion greatly exacerbates cell death, implying a role for the afferent inputs 
as well as the target (Furber et al., 1987). The role of the preganglionics may be more significant for the choroid neurons.

The ciliary ganglion is a convenient model for testing the generality of the role of target interactions in cell death. The 2 relatively homogeneous cell populations innervate 2 distinct targets. Each neuronal population appears to be governed by a unique set of rules. This certainly seems to be the case in vivo (see Meriney et al., 1987), and is likely the case in vitro as well. Much of the data supporting the present understanding of neuronal cell death comes from ncurons inncrvating striated muscle targets. The data in this study suggest that any assumption that the same relationship is general for all neurons is premature.

\section{References}

Adler, R., K. B. Landa, M. Manthorpe, and S. Varon (1979) Cholinergic neuronotrophic factors: II. Intraocular distribution of trophic activity for ciliary neurons. Science 204: 1434-1436.

Barde, Y.-A., D. Edgar, and H. Thoenen (1983) New neuronotrophic factors. Annu. Rev. Physiol. 45: 601-612.

Bennett, M. R., and V. Nurcombe (1979) The survival and development of cholinergic neurons on skeletal muscle conditioned media. Brain Res. 173: 543-548.

Bennett, M. R., and W. White (1979) The survival and development of cholinergic neurons in potassium-enriched media. Brain Res. 173: 549-553.

Berg, D. K. (1982) Cell death in neuronal development (regulation by trophic factors). In Neuronal Development, N. C. Spitzer, ed., pp. 297-331, Plenum, New York.

Berg, D. K. (1984) New neuronal growth factors. Annu. Rev. Neurosci. 7: 149-170.

Bonyhady, R. E., I. Hendry, C. E. Hill, and I. S. McClennan (1980) Characterization of a cardiac muscle factor required for the survival of cultured parasympathetic neurons. Neurosci. Lett. 18: 197-201.

Chamley-Campbell, J., R. Campbell, and R. Ross (1979) The smonth muscle cell in culture. Physiol. Rev. 59: 1-60.

Colucci, W. S., T. A. Black, M. A. Gimbrone, and R. W. Alexander (1984) Regulation of alpha-adrenergic receptor coupled calcium flux in cultured vascular smooth muscle cells. Hypertension 6: 119-124.

Crean, G., G. Pilar, J. B. Tuttle, and K. Vaca (1982) Enhanced chemosensitivity of chick parasympathetic neurones in co-culture with myotubes. J. Physiol. (Lond.) 331: 87-104.

Creazzo, T. L., and G. S. Sohal (1979) Effects of chronic injections of alpha-bungarotoxin on embryonic cell death. Exp. Neurol. 66: 135145.

Creedon, D. J., and J. B. Tuttle (1986) Failure of vascular smooth muscle to support the survival of cultured ciliary ganglion neurons. Soc. Neurosci. Abstr. 12: 1111 .

Davies, A. M., C. Bandtlow, R. Heumann, S. Korsching, H. Rohrer, and $H$. Thoenen (1987) Timing and site of nerve growth factor synthesis in developing skin in relation to innervation and expression of the receptor. Nature $326: 353-358$.

Ebendal, T., L. Olson, A. Seiger, and K. D. Hedlund (1980) Nerve growth factor in the rat iris. Nature 286: 25-28.

Fairbanks, G., T. L. Steck, and D. F. H. Wallach (1971) Electrophoretic analysis of the major polypeptides of the human erythrocyte membrane. Biochemistry 10: 2606-2617.

Fatigati, V., and R. A. Murphy (1984) Actin and tropomyosin variants in smooth muscles (dependence on tissue type). J. Biol. Chem. 259: 14383-14388.

Fischbach, G. D., L. W. Role, and R. I. Hume (1984) The accumulation of acetylcholine receptors at nerve-muscle synapses in culture. In Cellular and Molecular Biology of Neuronal Development, I. B. Black, ed., pp. 107-115, Plenum, New York.

Frankfurter, A., L. I. Binder, and L. R. Rebhun (1986) Identification of a neuron-specific beta-tubulin. Soc. Ncurosci. Abstr. 12: 1123.

Furber, S., R. W. Oppenheim, and D. Prevette (1987) Naturally-occurring neuron death in the ciliary ganglion of the chick embryo following removal of preganglionic input: Evidence for the role of afferents in ganglion cell survival. J. Neurosci. 7: 1816-1832.

Furukawa, Y., S. Furukawa, E. Satoyoshi, and K. Hayashi (1984) Nerve growth factor secreted by mouse heart cells in culture. J. Biol. Chem. 259: $1259-1264$.
Gabbiani, G. E., O. Kochcr, W. S. Bloom, J. Vandekerckhove, and K. Weber (1984) Actin expression in smooth muscle cells of rat aortic intimal thickening, human atheromatous plaque, and cultured rat aortic media. J. Clin. Invest. 73: 148-152.

Gray, D. B., and J. B. Tuttle (1987) ( $\left.{ }^{3} \mathrm{H}\right)$ Acetylcholine synthesis in cultured ciliary ganglion neurons: Effects of myotube membranes. Dev. Biol. 119: 290-298.

Greene, L. A., and E. M. Shooter (1980) The nerve growth factor: Biochemistry, synthesis and mechanism of action. Annu. Rev. Neurosci. 3: 353-403.

Gunther, S., W. Alexander, W. J. Atkinson, and M. A. Gimbrone (1982) Functional angiotensin II receptors in cultured vascular smooth muscle cells. J. Cell Biol. 92: 289-298.

Hamburger, V., and H. L. Hamilton (1951) A series of normal stages in the development of the chick cmbryo. J. Morphol. 88: 49-92.

Hamburger, V., and R. Levi-Montalcini (1949) Proliferation, differentiation, and degeneration in the spinal ganglia of the chick embryo under normal and experimental conditions. J. Exp. Zool. 111: 457502.

Hamburger, V., J. K. Brunso-Bechtold, and J. W. Yip (1981) Neuronal death in the spinal ganglia of the chick embryo and its reduction by nerve growth factor. J. Neurosci. 1: 60-71.

Heacock, A. M., A. R. Schonfeld, and R. Katzman (1986) Hippocampal neurotrophic factor: Characterization and response to denervation. Brain Res. 363: 299-306.

Helfand, S. L., G. Smith, and N. K. Wessels (1976) Survival and development in culture of dissociated parasympathetic neurons from ciliary ganglia. Dev. Biol. 50: 541-547.

Landa, K. B., R. Adler, M. Manthorpe, and S. Varon (1980) Cholinergic neurotrophic factors. III. Developmental increase of trophic activity for chick embryo ciliary ganglion neurons in their intraocular target tissues. Dev. Biol. 74: 401-408.

Landmesser, L., and G. Pilar (1974a) Synapse formation during embryogenesis in ganglion cells lacking a periphery. J. Physiol. (Lond.) 241: 715-736.

Landmesser, L., and G. Pilar (1974b) Synaptic transmission and cell death during normal ganglionic development. J. Physiol. (Lond.) 241: 737-749.

Landmesser, L., and G. Pilar (1978) Interactions between neurons and their targets during in vivo synaptogenesis. Fed. Proc. 37: 2016-2022.

Lee, M., J. B. Tuttle, and A. Frankfurter (1987) Pattern of expression of a neuron-specific beta-tubulin in early developmental stages of chick embryo. Soc. Neurosci. Abstr. 13.

Levi-Montalcini, R. (1982) Developmental neurobiology and the natural history of nerve growth factor. Annu. Rev. Neurosci. 5: 341362.

Manthorpe, M., and S. Varon (1985) Regulation of neuronal survival and neuritic growth in the avian ciliary ganglion by trophic factors. In Growth and Maturation Factors, G. Guroff, ed., pp. 77-117, Wiley, New York.

Manthorpe, M., G. E. Davis, and S. Varon (1985) Purified proteins acting on cultured chick embryo ciliary ganglion neurons. Fed. Proc. 44: 2753-2759.

Martin, W., and J. L. Gordon (1983) Spontaneous and agonist-induced $\mathrm{Rb}$ efflux from rabbit aortic smooth muscle cells in culture: $\mathrm{A}$ comparison with fresh tissue. J. Cell Physiol. 115: 53-60.

Marwitt, R., G. Pilar, and J. N. Weakly (1971) Characterization of two ganglion cell populations in avian ciliary ganglion. Brain Res. 25: 317-334.

Meriney, S. D., and G. Pilar (1987) Cholinergic innervation of the smooth muscle cells in the choroid coat of the chick eye and its development. J. Neurosci. 7: 3827-3839.

Meriney, S. D., D. B. Gray, and G. Pilar (1985) Morphine-induced delay of normal cell death in the avian ciliary ganglion. Science 228 : 1451-1453.

Meriney, S. D., G. Pilar, M. Ogawa, and R. Nuñez (1987) Differential neuronal survival in the avian ciliary ganglion after chronic acetylcholine receptor blockade. J. Neurosci. 7: 3840-3849.

Narayanan, C. H., and Y. Narayanan (1978) Neuronal adjustments in developing nuclear centers of the chick embryo following transplantation of an additional optic primordium. J. Embryol. Exp. Morphol. 44: 53-70.

Nishi, R., and D. K. Berg (1977) Dissociated ciliary ganglion neurons in vitro: Survival and synapse formation. Proc. Natl. Acad. Sci. USA 74: $5171-5175$. 
Nishi, R., and D. K. Berg (1979) Survival and development of ciliary ganglion neurons grown alone in cell culture. Nature 277: 232-234.

O'Farrel, P. H. (1975) High resolution two-dimensional electrophoresis of proteins. J. Biol. Chem. 250: 4007-4021.

Okado, N., and R. W. Oppenheim (1984) Cell death of motoneurons on the chick embryo spinal cord. IX. The loss of motoneurons following removal of afferent inputs. I. Neurosci. Res. 4: 1639-1652.

Olek, A. J. (1980) Effects of alpha and beta bungarotoxin on motor neuron loss in Xenopus larvae. Neuroscience 5: 1557-1563.

Oppenheim, R. W. (1981) Neuronal cell death and some related regressive phenomena during neurogenesis: A selective review and progress report. In Studies in Developmental Neurobiology: Essays in Honor of Victor Hamburger, M. W. Cowan, ed., pp. 74-133, Oxford U. P., New York.

Oppenheim, R. W., and R. Nuñez (1982) Electrical stimulation of hindlimb increases neuronal cell death in chick embryo. Nature 295 : $57-59$.

Owens, G. K., A. Loeb, D. Gordon, and M. M. Thompson (1986) Expression of smooth muscle-specific alpha-isoactin in cultured vascular smooth muscle cells: Relationship between growth and cytodifferentiation. I. Cell Biol. 102: 343-352.

Paul, J. (1970) Cell and Tissue Culture, Livingstone, Edinburgh.

Pilar, G., and L. Landmesser (1976) Ultrastructural differences during embryonic cell death in normal and peripherally deprived ciliary ganglia. J. Cell Biol. 68: 339-356.

Pilar, G., L. Landmesser, and L. Burstein (1980) Competition for survival among developing ciliary ganglion cells. J. Neurophysiol. 63 . 233-254.

Pittman, R. H., and R. W. Oppenheim (1978) Neuromuscular blockade increases motoneuron survival during normal cell death in the chick embryo. Nature 271: 364-366.

Pittman, R., and R. W. Oppenheim (1979) Cell death of motoneurons in the chick embryo spinal cord. IV. Evidence that a functional neuromuscular interaction is involved in the regulation of naturally occurring cell death and the stabilization of synapses. J. Comp. Neurol. 187: 425-446.

Purdy-Ramos, S. I., and M. S. Forbes (1984) The preparation of cultured cells of vascular origin for transmission electron microscopy. J. Electron Microsc. Tech. I: 271-277.
Purves, D., and J. W. Lichtman (1985) Principles of Neuronal Development, Sinauer, Sunderland, MA.

Purves, R. D. (1981) The physiology of smooth muscle cells in tissue culture. In Excitable Cells in Tissue Culture, P. G. Nelson and M. Lieberman, eds., pp. 341-357, Plenum, New York.

Role, L. W., V. R. Matossian, J. O'Brien, and G. D. Fischbach (1985) On the mechanism of acetylcholine receptor accumulation at newly formed synapses on chick myotubes. J. Neurosci. Res. 5: 2197-2204.

Rush, R. A. (1984) Immunohistochemical localization of endogenous nerve growth factor. Nature 312: 364-367.

Shelton, D. L., and L. F. Reichardt (1984) Expression of the B-nerve growth factor gene correlates with the density of sympathetic innervation in effector organs. Proc. Natl. Acad. Sci. USA 81: 7951-7955.

Skaper, S. D., I. Selak, M. Manthorpe, and S. Varon (1984) Chemically defined requirements for the survival of cultured 8-day chick embryo ciliary ganglion neurons. Brain Res. 302: 281-290.

Thoenen, H., and Y.-A. Barde (1980) Physiology of nerve growth factor. Physiol. Rev. 60: 1284-1335.

Thoenen, H., and D. Edgar (1985) Neurotrophic factors. Science 229: 238-242.

Touzeau, G., and A. C. Kato (1983) Effects of amyotrophic lateral sclerosis sera on cultured cholinergic neurons. Neurology 33: 317322.

Tuttle, J. B. (1983) Interaction with membrane remnants of target myotubes maintains transmitter sensitivity of cultured neurons. Science 220: 977-979.

Tutlle, J. B., J. Suszkiw, and M. Ard (1980) Long term survival and development of dissociated parasympathetic neurons in cell culture. Brain Res. 183: 161-180.

Tuttle, J. B., K. Vaca, and G. Pilar (1983) Target influences on 3H $\mathrm{ACH}$ synthesis and release by ciliary ganglion neurons in vitro. Dev. Biol. 97: 255-263.

Varon, S., M. Manthorpe, and R. Adler (1979) Cholinergic neuronotrophic factors: I. Survival neurite outgrowth and choline acetyltransferase activity in monolayer cultures from chick embryo ciliary ganglion. Brain Res. 173: 29-45.

Wright, L. (1981) Cell survival in chick embryo ciliary ganglion is reduced by chronic ganglionic blockade. Dev. Brain Res. 1: 283-286. 